Kiryoku, Volume 3 No 42019

e-ISSN: 2581-0960 p-ISSN: 2599-0497

Tersedia online di http://ejournal.undip.ac.id/index.php/kiryoku

\title{
Implementasi Shibori Di Indonesia
}

\author{
Siti Maziyah*, Sri Indrahti, Alamsyah \\ Departemen Sejarah Fakultas Ilmu Humaniora Universitas Diponegoro \\ *E-mail : mazy_muiz@yahoo.com
}

\begin{abstract}
Abstrak
Shibori adalah teknik membuat motif kain serupa batik yang dilakukan di Jepang.Akhir-akhir ini teknik tersebut banyak digemari oleh warga Indonesia karena tekniknya yang lebih sederhana dan pembuatannya lebih cepat dari pada membatik. Sebetulnya teknik ini serupa dengan membatik, yaitu melakukan perintangan warna agar tercipta motif pada kain.Jika pada batik alat perintang yang digunakan adalah lilin malam, maka pada shibori yang digunakan dapat dari berbagai alat seperti karet, benang, jepitan, dan sebagainya. Berdasarkan penelusuran pada budaya pembuatan motif kain tradisional di Indonesia, ternyata teknik shibori juga telah dilakukan oleh para pengrajin kain di Indonesia. Seperti apakah implementasi shibori di Indonesia itu?Dengan menggunakan studi pustaka dari berbagai tulisan yang berkaitan dengan pembuatan motif kain, akhirnya dapat ditelisik beberapa teknik shibori yang sudah dilakukan oleh para pengrajin kain tradisional di Indonesia.
\end{abstract}

Kata kunci: implementasi; shibori; batik; motif kain; Indonesia

\begin{abstract}
(Title: Shibori Implementation in Indonesia) Shibori is a technique for making batik-like cloth motifs carried out in Japan. Lately, this technique has been favored by many Indonesians because of its simpler technique and faster production than batik making. Actually this technique is similar to batik, which is doing a color barrier to create a motif on the fabric. If in batik the barrier device used is wax, then the shibori used can be from various tools such as rubber, yarn, clothespin, and so on. Based on a search on the culture of making traditional fabric motifs in Indonesia, it turns out that the shibori technique has also been carried out by fabric artisans in Indonesia. What is the implementation of shibori in Indonesia like? By using literature studies from various writings relating to making fabric motifs, finally some shibori techniques can be investigated that have been carried out by traditional fabric artisans in Indonesia.
\end{abstract}

Keywords: implementation; shibori; batik; fabric motif; Indonesia

\section{PENDAHULUAN}

Ide untuk membuat artikel ini bermula dari kegiatan pengabdian yang kami lakukan pada semester genap 2019 ini yang bertema "Upaya Pemberdayaan Perempuan Melalui Pelatihan Pembuatan Jumputan dan Shibori Pada Ibu-Ibu GOW Kabupaten Demak". Tema pengabdian ini diselenggarakan karena akhir-akhir ini ibuibu dan remaja putri di Indonesia menggandrungi shibori, bahkan ada beberapa pengusaha muda yang menjadikan shibori sebagai lahan pekerjaannya. Oleh karena itu tujuan dari pengabdian ini adalah memberdayakan perempuan melalui pembuatan motif kain 
dengan teknik jumputan dan shibori. Harapannya suatu saat akan muncul interpreneur baru di bidang pembuatan motif kain dengan kedua teknik ini, setidaknya para peserta pelatihan dapat membuat motif kain dengan menggunakan kedua teknik ini (Maziyah, Indrahti, Alamsyah, 2019).

Apakah shibori itu? Shibori adalah teknik membuat motif kain serupa batik yang dilakukan di Jepang. Akhir-akhir ini teknik tersebut banyak digemari oleh warga Indonesia karena tekniknya yang lebih sederhana dan proses pembuatannya lebih cepat dari pada membatik. Sebetulnya teknik ini serupa dengan membatik, yaitu melakukan perintangan warna agar tercipta motif pada kain. Jika pada batik alat perintang yang digunakan adalah lilin atau sering disebut dengan malam, maka pada shibori perintang warnanya dapat dari berbagai alat seperti karet, benang nilon, jepitan, dan sebagainya.

Sebagaimana dengan batik, ternyata shibori juga menarik minat para peneliti. Penelitian pertama temanya berkaitan dengan eksplorasi teknik shibori untuk pengembangan desain motif tradisional Indonesia khususnya untuk kain sandang (Suantara, Oktaviani, dan Siregar, 2017). Tujuan penelitian ini adalah untuk membuat kain sandang bermotif tradisional Indonesia hasil dari eksplorasi teknik shibori yang berasal dari Jepang, namun di Indonesia teknik itu lebih dikenal dengan nama ikat celup (Gillow, 1992:30-32). Hasil penelitian menunjukkan bahwa teknik shibori yang memiliki cara yang lebih beragam dalam menciptakan motif kain ini diharapkan dapat memberikan wawasan pada pengrajin celup ikat bahwa beragam motif tradisional Indonesia dapat diaplikasikan dan dikembangkan pada kain ikat celup yang selama ini hanya menampilkan motif-motif sederhana yang dihasilkan dari ikat celup biasa.Pada penelitian kedua serupa dengan penelitian pertama, akan tetapi diterapkan pada pakaian siap pakai (Kautsar, 2017).

Pada penelitian ketiga, teknik shibori digunakan sebagai alternative untuk psychological health dan behavioral health dalam psychological first aid penyitas bencana (Juniati, Ninik; Yuwanto, 2018). Shibori dapat dimanfaatkan dalam program psychological first aid penyintas bencana, karena adanya kegiatan yang bermakna dalam mengerjakannya, sehingga akan menghasilkan perasaan positif serta menimbulkan potensi ekonomi. Pada kasus ini, penyintas bencana dapat mengalami ketidaknyamanan psikologis dan kehilangan mata pencaharian pasca bencana yang dapat ditangani dengan menggunakan shibori, sebagai salah satu ketrampilan yang dapat mendatangkan penghasilan.

Berdasarkan ketiga penelitian sebelumnya itu, dapat diketahui bahwa pada penelitian pertama dan kedua terdapat kesamaan ide untuk memperkaya motif tradisional melalui beberapa teknik yang dimiliki oleh shibori yang belum dilakukan oleh para pengrajin kain.Adapun penelitian ketiga menunjukkan bahwa shibori dapat digunakan untuk memberikan kenyamanan secara psikologis kepada masyarakat yang terdampak bencana.Oleh karena itu, ketiga penelitian sebelumnya belum menujukkan secara langsung teknik shibori yang telah dilakukan oleh para pengrajin kain tradisional di Indonesia.Berdasarkan penelusuran pada budaya pembuatan motif kain tradisional di Indonesia, ternyata teknik shibori ini telah diimplementasi atau diterapkan oleh para pengrajin kain di Indonesia. Seperti apakah implementasi shibori di Indonesia itu?

Tujuan penulisan artikel ini adalah untuk menunjukkan bahwa Indonesia memiliki kekayaan budaya dalam teknik pembuatan motif hias pada kain tradisional serupa dengan shibori, yaitu teknik pembuatan kain pada budaya Jepang. 
Kiryoku, Volume 3 No 42019

e-ISSN: 2581-0960 p-ISSN: 2599-0497

Tersedia online di http://ejournal.undip.ac.id/index.php/kiryoku

\section{METODE}

Penelitian ini merupakan penelitian yang berbasis studi pustaka. Beberapa kata kunci pada abstrak adalah implementasi; shibori; batik; motif kain; dan Indonesia.Oleh karena itu, topik artikel hasil penelitian serta buku yang dicari adalah yang berkaitan dengan kata kunci tersebut, terutama berkaitan dengan shibori, batik, dan motif kain di Indonesia. Selanjutnya dipelajari yang dimaksud dengan shibori itu teknik membuat motif kain yang bagaimana. Hal itu diperlukan, karena Indonesia juga memiliki berbagai teknik pembuatan motif kain dengan menggunakan nama lokal. Setelah diketahui kedua hal tersebut, baik teknik shibori maupun teknik lokal, maka kemudian dapat disimpulkan teknik shibori yang bagaimana yang telah dilakukan atau diimplementasikan oleh para pengrajin kain lokal itu.

\section{HASIL DAN PEMBAHASAN}

Kain merupakan salah satu kebutuhan dasar manusia untuk melindungi tubuhnya dari cuaca, kemudian berkembang fungsinya seiring dengan tingkat kebudayaan manusia itu sendiri. Kain dapat berfungsi secara teknis sebagai pakaian, secara ekonomi sebagai komoditas perdagangan, secara sosial sebagai penunjuk strata sosial pemakainya, dan secara religius digunakan untuk keperluan upacara keagamaan (Gavin, 2003; Maziyah, 2017b, 2017a, 2019; Maziyah, Mahirta, \& Atmosudiro, 2016).

Salah satu cara untuk menaikkan fungsi kain secara ekonomis, sosial serta untuk kepentingan dalam upacara keagamaan adalah pembuatan motif hiasnya. Secara universal masyarakat di berbagai wilayah di dunia ini telah memiliki cara untuk membuat motif pada kain, termasuk masyarakat di Indonesia. Pada artikel ini akan dibahas masalah teknik pembuatan kain shibori serta implementasinya di Indonesia.

\section{a. Teknik Shibori di Jepang}

Shibori merupakan salah satu seni pengolahan kain dari Jepang yang berkembang sejak abad ke-8. Pada mulanya, teknik pembuatan kain ini hanya digunakan untuk membuat kain tradisional di Jepang, yaitu kimono dari sutra dengan menggunakan pewarna alam indigofera yang menghasilkan warna biru (Juniati, Ninik; Yuwanto, 2018:3; Kautsar, 2017:908-909).

Istilah shibori berasal dari kata shiboru yang berarti memeras, menjepit, dan menekan. Banyak sekali teknik dalam pengolahan kain ini, oleh karena itu, shibori memiliki banyak nama menyesuaikan dengan teknik yang digunakan. Kain yang dihasilkan dari teknik ini termasuk dalam kelompok kain tradisional yang teknik pembuatan motifnya dikerjakan dengan resist and shape-resist dyeing yang umum disebut dengan istilah tie-dye atau ikat celup. Teknik ikat celup banyak ditemui di berbagai negara Afrika, seperti Senegal, Mali, Gambia, Sierra Leone, Burkina Faso, Nigeria, dan Kamerun. Negara-negara Asia seperti Mesir, Persia, India, Jepang dan Indonesia (Juniati, Ninik; Yuwanto, 2018; Maziyah, 2014:61).

Berdasarkan tiga artikel yang membahas masalah shibori di atas, ternyata terdapat berbagai cara untuk membuat motif kain dengan menggunakan teknik shibori. Tabel 1 berikut menunjukkan teknik membuat motif kain pada shibori berikut dengan istilah bahasa Jepang-nya.

Tabel 1. Berbagai Teknik Shibori

(Juniati; Yuwanto, 2018:11; Kautsar, 2017:7).

\begin{tabular}{lll}
\hline No & $\begin{array}{l}\text { Teknik Membuat } \\
\text { Motif Kain Shibori }\end{array}$ & Istilah Jepang \\
\hline 1. & Menjahit & Ori-nui shibori \\
2. & Mengikat & Kumo shibori \\
3. & Melilit & Sujishibori \\
4. & Melipat & Etajime shibori \\
5. & Menjumput & Kanoko shibori \\
6. & Menggunakan & Arashi shibori \\
& media pipa pralon & \\
7. & Memilin & \\
8. & Memelintir & \\
\hline
\end{tabular}


Proses pembuatan motif kain dengan teknik shibori dimulai dengan menggambar motif di atas kain, kemudian dilakukan salah satu atau kombinasi dari beberapa teknik shibori di atas, yaitu dengan cara menjahit, mengikat, melilit, melipat, menjepit, atau membungkus kain yang telah diberi pola itu dengan ketat menggunakan benang, karet, atau alat penjepit. Setelah itu, kain dicelup dengan menggunakan satu atau beberapa pewarna sesuai keinginan.Kain dapat dicelup beberapa kali untuk mendapatkan warna yang diinginkan sesuai dengan motif yang dibuat.

Berikut ini contoh motif kain dengan menggunakan teknik shibori itu.

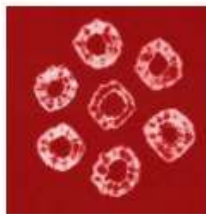

(a)

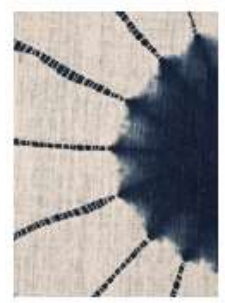

(c)

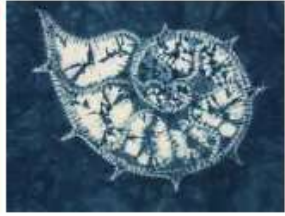

(b)

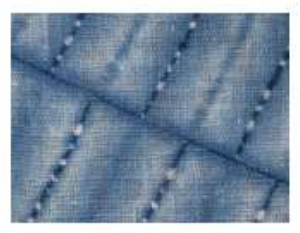

(d)

Gambar 1.Kanako Shibori (a), Nui Shibori (b), Kumo Shibori (c), dan Suji Shibori (d). (Suantara et al., 2017:70)

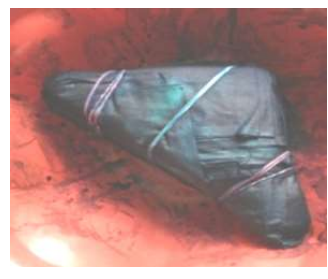

Gambar 2. Etajime Shibori (Maziyah, Indrahti, Alamsyah, 2019:7-8)
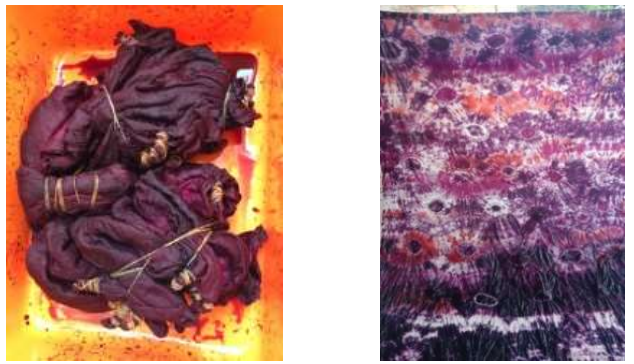

Gambar 3. Kombinasi teknik memelintir dan mengikat

(Maziyah, Indrahti, Alamsyah, 2019:6-7)

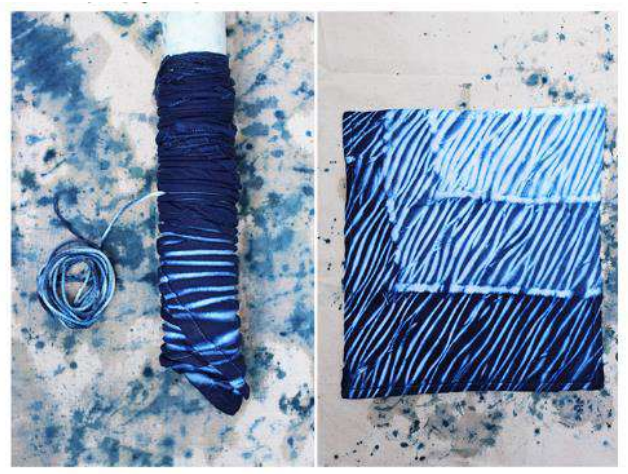

Gambar 4. Arashi Shibori

(Juniati; Yuwanto, 2018:6)

\section{b. Teknik Membuat Motif Kain Secara Tradisional di Indonesia}

Teknik membuat motif kain dengan cara melipat, memelintir, menjepit, dan mengulung pada pipa hanya digunakan pada teknik shibori Jepang. Sementara itu teknik ikat celup yang digunakan di negara selain Jepang pada umumnya menggunakan teknik stitch-resist dengan menggunakan benang yaitu dijelujur kemudian ditarik kuat-kuat, teknik mengikat dengan benang, tali maupun karet gelang (tying), baik ikatan besar maupun kecil.

Beberapa daerah di Indonesia juga telah memiliki teknik ikat celup untuk membuat motif kain.Masing-masing daerah itu meskipun menggunakan teknik yang serupa, akan tetapi disebut dengan istilah lokal yang berbeda sesuai dengan daerah kebudayaannya. Oleh karena itu, nama yang tersematkan pada kain itu kemudian sesuai dengan nama teknik yang digunakan dan kemudian menjadi kain 
Kiryoku, Volume 3 No 42019

e-ISSN: 2581-0960 p-ISSN: 2599-0497

Tersedia online di http://ejournal.undip.ac.id/index.php/kiryoku

khas daerah tersebut. Tabel 2 berikut ini menjelaskan informasi di atas.

Tabel 2. Teknik Pembuatan Motif Kain di Indonesia dan Istilah Lokalnya (Gartha, 2013:5-12)

\begin{tabular}{|c|c|c|c|}
\hline No & $\begin{array}{l}\text { Teknik } \\
\text { pembuatan } \\
\text { motif kain }\end{array}$ & $\begin{array}{l}\text { Istilah } \\
\text { Lokal }\end{array}$ & Daerah \\
\hline 1 & $\begin{array}{l}\text { Mengikat } \\
\text { sejumput kain }\end{array}$ & $\begin{array}{l}\text { Jumputan } \\
\text { Plangi } \\
\text { Roto }\end{array}$ & $\begin{array}{l}\text { Jawa } \\
\text { Palembang } \\
\text { Toraja }\end{array}$ \\
\hline 2 & $\begin{array}{l}\text { Menjahit } \\
\text { jelujur sesuai } \\
\text { dengan pola } \\
\text { yang } \\
\text { digambar }\end{array}$ & $\begin{array}{l}\text { Tritik } \\
\text { Sasirangan }\end{array}$ & $\begin{array}{l}\text { Jawa } \\
\text { Kalimantan }\end{array}$ \\
\hline
\end{tabular}

Adapun penjelasan dari masing-masing jenis kain itu adalah sebgai berikut.

\section{1). Jumputan}

Kain ini disebut dengan jumputan, karena cara membuatnya adalah dengn cara menjumput, yaitu mengambil ujung kain kemudian diikat dengan kencang. Sebelum diikat, ujung kain dapat diberi kelereng atau manik-manik kecil agar bulatannya rata dan terlihat rapi. Motif kain muncul dari kain yang diikat setelah dilakukan pencelupan ke dalam bahan pewarna kain.Secara tradisional, kain jumputan ini biasanya digunakan sebagai ikat pinggang atau sebagai selendang untuk penari (sampur). Pada saat ini jumputan digunakan sebagai berbagai keperluan, baik untuk keperluan fashion hingga interior.

\section{2). Plangi}

Teknik pembuatan kain plangi serupa dengan jumputan. Hal yang membedakan adalah digunakannya berbagai warna, sehingga kain ini dinamakan kain plangi. Berbagai warna itu dibuat dengan cara mencolet pada kain yang masih berwarna putih. Kain ini biasanya menggunakan bahan dari sutra, dan biasanya digunakan sebagai selendang atau baju kurung.

\section{3). Roto}

Teknik jumputan juga digunakan di Tana Toraja, yang diaplikasikan pada kain tenun yang berasal dari pintalan kapas.Kain roto ini merupakan kain yang sakral, karena biasanya digunakan sebagai alat perlengkapan upacara tradisi masyarakat Tana Toraja.

\section{4). Tritik}

Tritik merupakan salah satu jenis kain yang cara pembuatan motif hiasnya dengan jalan dijelujur, sehingga menghasilkan garisgaris yang terdiri dari titik-titik kecil. Di Jawa, teknik ini diaplikasikan pada kain kembangan dan digunakan sebagai kemben. Teknik ini kadang-kadang diaplikasikan bersamaan dengan batik pada kain dodot atau kampuh, salah satu kain yang digunakan untuk upacara tradisi Jawa.

\section{5). Sasirangan}

Teknik serupa tritik dipakai di Kalimantan dengan namasasirangan, yang berasal dari kata sirang yang berarti jelujur, yaitu cara untuk membuat motif hias kain itu. Proses pembuatan motif kain diawali dengan menggambar motif kain dengan menggunakan pensil, kemudin dijelujur dengan menggunakan benang nilon, ditarik dan diikat kencang, serta dicelup pada pewarna. Setelah selesai proses pewarnaan maka akan muncul motif seperti yang teal digambar dengan menggunakan pensil tadi. Adapun masing-masing motif kain tradisional Indonesia yang dihasilkan dari beberapa teknik itu adalah seperti berikut ini.
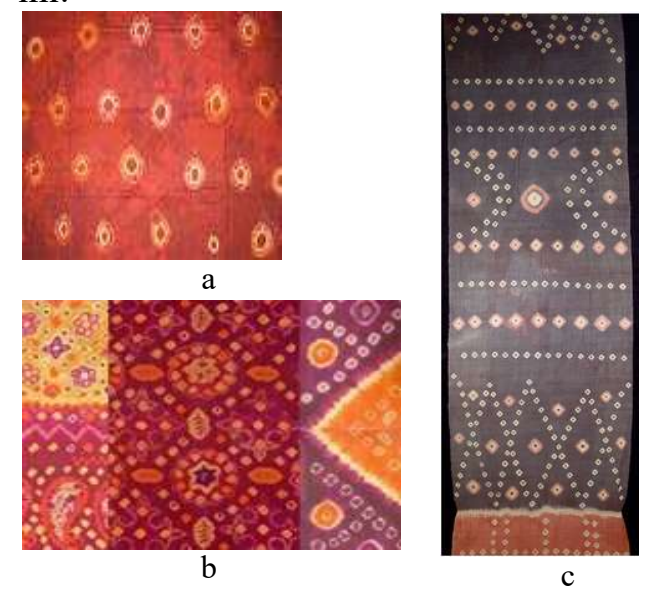

Gambar 5. Jumputan (a), Plangi (b), dan Roto (c) (Maziyah, 2014:64) 


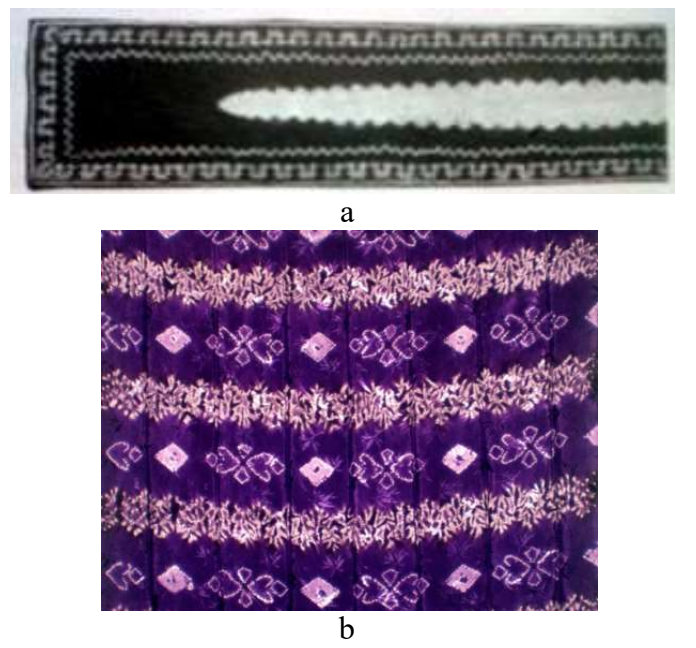

Gambar 6. Tritik dan Sasirangan (Maziyah, 2014:64-65)

Berdasarkan tabel 2 di atas, dapat diketahui bahwa teknik ikat celup yang dilakukan di Indonesia meskipun ditemukan lima istilah ikat celup, sebenarnya hanya menggunakan dua teknik saja, yaitu mengikat dan menjumput, serta menjelujur sesuai dengan pola hias kain yang diinginkan. Oleh karena itu, meskipun memiliki istilah yang berbeda, tetapi masing-masing motif itu serupa karena menggunakan teknik yang sama untuk membentuk motifnya seperti yang terlihat gambar 5 dan gambar 6 .

Oleh karena itu, tepat kiranya yang diusulkan oleh Suantara, et al (2017) yang mengatakan bahwa diperlukan beberapa teknik shibori yang lain di Indonesia untuk lebih memperkaya pembutan motif kain. Seperti yang telah dilakukan oleh beberapa workshop kekinian yang menjual kain shibori sebagai salah satu unggulan dagangnya. Contohnya Rumah Batik Komar di Bandung yang dimiliki oleh Putri Komar yang menggabungkan batik dengan shibori pada workshopnya, dan memiliki target penjualan untuk anak muda umur 20-30 tahun (https://www.google.com/amp/s/m.kumpar an.com/amp/kumparanstyle/putri-komardiremehkan-lalu-sukses-kawinkan-batikdengan-shibori).

\section{SIMPULAN}

Berdasarkan pembahasan di atas, dapat diketahui bahwa para pengrajin kain tradisional di Indonesia telah mengenal dan mengimplementasikan beberapa teknik shibori pada pembuatan motif kainnya. Dari delapan cara untuk membuat motif kain shibori, para pengrajin kain tradisional di Indonesia telah menggunakan dua jenis cara, yaitu menjumput kemudian mengikat, dan menjelujur kain sesuai dengan motif yang diinginkan kemudian ditarik dan diikat. Dua cara membuat motif hias pada kain tradisional itu di Jawa, Palembang, Kalimantan, dan Sulawesi disebut dengan lima istilah, yaitu jumputan, plangi, roto, tritik, dan sasirangan.

\section{REFERENSI}

Buku

Gartha, Benny. (2013). Panduan Pembuatan Kain Ikat Celup Bagi Pemula. Jakarta: Museum Tekstil.

Gavin, Traude. (2003). "Iban Ritual Textiles". Verhandelingen van het Koninklijk Instituut voor Taal-, Land- en Volkenkunde. 205. Leiden: KITLV Press.

Gillow, John. (1992). London: Thames and Hudson, Ltd.

\section{$\underline{\text { Artikel Jurnal }}$}

Juniati, Ninik dan Listyo Yuwanto. (2018). "Pemanfaatan Seni Shibori Sebagai Alternatif Psychological Health Behavioral Health dalam Psychological First Aid Penyintas Bencana". Seminar Nasional Peranan Ilmu Psikologi Dalam Penanggulangan Bencana. Surabaya: Fakultas Psikologi Universitas Surabaya. 
Kiryoku, Volume 3 No 42019

e-ISSN: 2581-0960 p-ISSN: 2599-0497

Tersedia online di http://ejournal.undip.ac.id/index.php/kiryoku

Kautsar, Dinda Siti. (2017). "Eksplorasi Teknik Shibori Pada Pakaian Ready to Wear". E-Poceeding of Art \& Design. Vol 4. No. 3. Hlm. 905-920.

Maziyah, Siti. (2014). "Batik as an Indonesian National Identity". International Seminar Proceeding "Strengthening National Identity through Language, Literature, and History". Semarang: Faculty of Humanities Diponegoro University and Faculty of Education and human Development Nagoya University Japan.

Maziyah, Siti, Mahirta, \& Atmosudiro. (2016). "Makna Simbolis Batik Pada Masyarakat Jawa Kuna". Paramita. Vol. 26. No. 1. Hlm. 2332.

https://journal.unnes.ac.id/nju/inde x.php/paramita/article/5143

Maziyah, Siti, (2017a). "Fungsi Kain Impor di Jawa Pada Abad Ke-9 ke-15 Berdasar Sumber Arkeologis". Studen Weekly. Yogyakarta: Fakultas Ilmu Budaya Universitas Gadjah Mada. http://fib.ugm.ac.id/2017/04/fungsikain-import-di-jawa-pada-abad-ke9-ke-15-berdasar-sumberarkeologis.html.

(2017b). "Imports Fabric at Java in $12^{\text {th }}-14^{\text {th }}$ Centuries: Impacts of Maritime Trade Route in Southeast Asia". Advanced Science Letters. Vol. 23. No. 10. Hlm. 1005710060 .

. (2019). "Teknik Pembuatan dan Fungsi Kain Pada Masyarakat Jawa Kuna Abad ke-9 hingga abad ke-15 Berdasar Data Arkeologi”. Disertasi. Yogyakarta: Fakultas Ilmu Budaya Universitas Gadjah Mada.
Maziyah, Siti, Indrahti, Sri, Alamsyah (2019). "Upaya Pemberdayaan Perempuan Melalui Pelatihan Pembuatan Jumputan danShibori Pada Ibu-Ibu GOW Kabupaten Demak". Laporan Pengabdian Kepada Masyarakat. Semarang: Fakultas Ilmu Budaya Universitas Diponegoro.

Suantara, Oktaviani, dan Siregar, (2017). "Eksplorasi Teknik Shibori Dalam Pengembangan Desain Motif Tradisional Indonesia Pada Permukaan Kain Sandang". Arena Tekstil. Vol. 32. No. 2. Hlm. 67-76.

"Putri Komar Diremehkan Lalu Sukses Kawinkan Batik dengan Shibori", https://www.google.com/amp/s/m. kumparan.com/amp/kumparanstyle /putri-komar-diremehkan-lalusukses-kawinkan-batik-dengan$\underline{\text { shibori }}$ 